\title{
Role Of Public Service Awareness Messages In Developing Precautionary Attitude Towards Breast Cancer Detection Among Pakistani Women
}

\author{
Moneeba Iftikhar \\ Department of Mass Communication \\ Lahore College for Women University \\ Zahid Yousaf \\ Centre for Media and Communication Studies (CMCS) \\ University of Gujrat
}

\begin{abstract}
The study was aimed at scrutinizing the effects of the Public Service Awareness Messages about breast cancer detection among women in terms of developing precautionary measures for the life-threatening disease in order to fight against it before time. Breast Cancer is the most common cancer among the women around the world and especially in Pakistan. The study has been carried out with a survey with 300 women of Lahore, Pakistan and found that Public Service Awareness Messages have been significantly perceived by them. PSAMs are important tool for providing information and spreading awareness regarding the disease. The fear appeal of the messages changed the behavior of the viewers for taking precautionary measures. Public Service Awareness Messages regarding healthcare make people conscious about their health and they believe that precautionary measures can prevent the dreadful comings of this disease.
\end{abstract}

Keywords: Public Service Awareness Messages, Precautionary Measures, Breast Cancer.

$$
\begin{aligned}
& \text { تلخيص }
\end{aligned}
$$

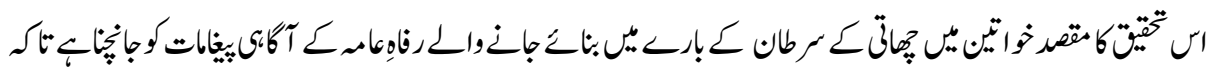

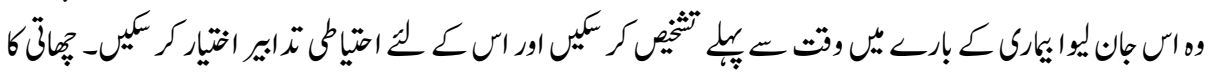

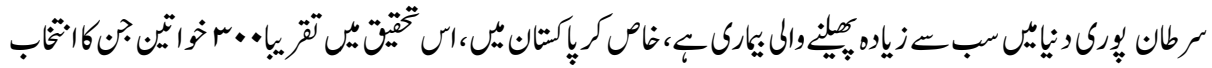

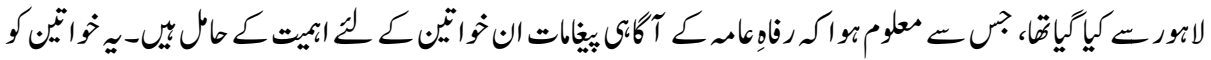

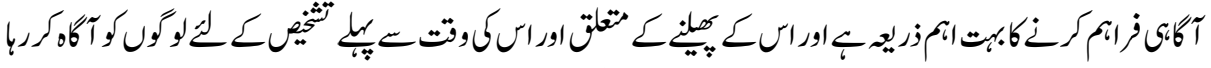

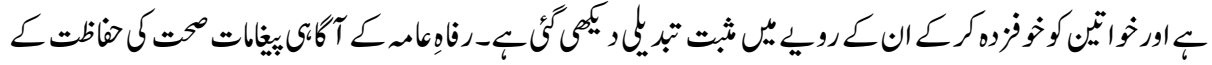

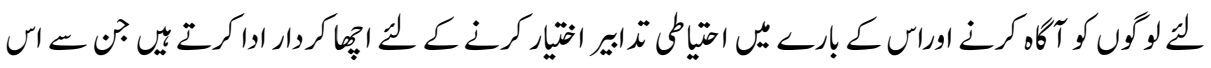

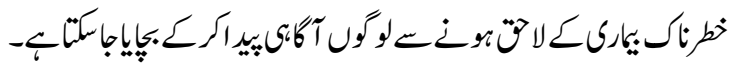

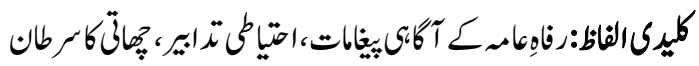

This work is Licensed under a Creative Commons Attribution-NonCommercial 4.0 International License (c) () () 


\section{Introduction}

Television is an important source of informing about health to the public. Public Service Messages (PSM) are the source by which Public Health Sector can inform people about important health issues. Public health informers need to look for other agendas for impacting TV content, like media advocacy (Wallack \& Dorfman, 1992). Public Service Messages (PSM) are noncommercial ads that changes public opinion and behavior by creating consciousness about certain problems (Klimes, Dougan \& Lee, 2010).

Public Service Awareness Message (PSAM) is designed to educate the audience with the collaboration of ad agencies and non-profit organizations about a particular issue instead of selling some type of product. The importance of Public Service Awareness Message is increased by giving them prime time slot. Public Service Awareness Messages are significant to inform and form public consent about social problems which are usually non-controversial.

Health issues are highly addressed through PSAM for promoting healthy behavior considering health important. Health is "a state of complete physical, mental and social well-being, not merely the absence of disease or infirmity" (WHO, 1946). Health issues or diseases are the threat to life among which cancer is a dangerous one. The abnormal growth of cells in body cause cancer that transforms into tumor. Breast cancer targets the breast tissues and appears with malignant cell growth that can spread to other parts of the body if left untreated. Cancer statistics 2019 states: "breast cancers are most common among women, Prostate and lung; breast cancer alone accounts for 30\% of all new cancer diagnoses in the year in women" (Siegel, Miller \& Jemal, 2019).

October is celebrated as "Breast Cancer Awareness" month by World Health Organization to formally address the issue. The renowned organization for healthy world decides this upon the study there were around four hundred and fifty-eight thousand deaths and 1.38 million sufferers of breast cancer recorded every year in India (IARC Globocan, 2008; Katkuri \& Gorantla, 2018).

2008 GLOBOCAN of WHO reports that Breast cancer is found globally common among over 1.38 million women. The detection is done by mammogram before any symptom appears. Early detection is very important for the effective treatment. This cancer is targeting women from every age and causing social and financial issues.

Pakistan is an under developed country where a bigger portion of population lives in villages. Unaware and illiterate population has minimum knowledge about diseases and symptoms like breast cancer disease in Pakistani women. The awareness regarding breast cancer started with the efforts of Mr. Omer Aftab who founded Pink Ribbon Foundation in 2003 after he witnessed the death of his friend due to the killer disease. It is alarming 
under the light of his report that around 90,000 breast cancer cases are reported every year in Pakistan. Moreover he states that more than 40,000 collapsed carrying breast cancer due to late diagnosis. And lastly the report signposts that 10.2 million Pakistani females are at a risk of being caught by this disease.

Breast cancer has become a dilemma from its deterrence to its diagnosis, and then the tedious journey of its treatment contain many health issues globally. Talking about United States of America, most of the females have revelation to this illness (Coughlin \& Ekwueme, 2009).That's why it is important to inform society about its detection in order to develop a precautionary behavior. In this way women can be motivated to be conscious in monitoring themselves by early detection and can be able to save their lives.

Most of the time celebrities and journalists are being used in breast cancer awareness messages, but many studies recommend such messages frequently extant improper and inadequate information in health matters (Dornbusch \& Daniel, 1998) (MacKenzie, Chapman, Barratt, \& Holding, 2007) (Moynihan, et al., 2000) (Nakahara, Ichikawa \& Wakai, 2007) (Pruitt, \& Mullen, 2005).For instance, PSAM about breast cancers often reports hereditary factors as a primary factor in women's hazard for breast cancer in females, with an estimate of 5 to 10 percent of a female's risk (Ogata Jones, Denham, \& Springston, 2006) (Henderson \& Kitzinger, 1999) (Sagi, Kaduri, Zlotogora \& Peretz, 1998) (American Cancer Society, Inc. 2006). Although media is trying to disseminate information to the public in effective way and concepts but women are found weak in changing their attitude towards self-monitoring for early detection (Chaffee, 1982). As a result it's the need of time for communication experts to find the root cause of this lethargic behaviour. One of the study shows that a combination of media interpersonal communication together can work to stimulate health behavior of women (DuttaBergman, 2004).

According to (Global Burden of Disease Cancer Collaboration, 2015), the world is assumed to be hampered with more than 2 million cases of breast cancer by 2030. From developing or developed countries of the world, the disease is mostly developing among women (Katkuri\& Gorantla, 2018). This type is the most developing cancer with $23 \%$ (almost a quarter) representation, among all the cancers developing in women (Ferlay, et. al., 2015).

In the whole Asia, Pakistan has witnessed the most breast cancer cases (Banning, \& Tanzeen, 2019). It usually targets older age women usually after 50 years (Banning \& Tanzeen, 2019; Kaushal, et. al., 2019; Linsell, Burgess\& Ramirez, 2008). To build a behavior of precaution towards this disease, this health problem needs to be addressed.

There is an immediate need to inform people about the threats and precautions, in the situation where this disease is so common and spreading all around the world. Having no 
or very less understanding of the disease and the hindrance in the detection can complicates the case (da Costa et. al., 2017) and extend the prospects of it becoming incurable as it is the second crucial reason of death among women according to UK's Office of National Statistics.

The aim of present study is determined at finding the awareness of breast cancer among women and precautionary measures of breast cancer in women and also measuring the behavioral intention of women after watching Public Service Awareness Messages about breast cancer.

The objectives of the study are

- To evaluate the awareness created by Public Service Awareness Messages (PSAMs) among women about breast cancer.

- To scrutinize the changing behavior of women created by Public Service Awareness Messages (PSAMs) about breast cancer precautionary measures.

- To analyze the content effectiveness of Public Service Awareness Messages (PSAMs) based on breast cancer.

- To study the behavior of women towards their health for taking precautionary measures against breast cancer after watching Public Service Awareness Messages (PSAMs).

\section{Rationale of the Study}

Public service advertising has a powerful role in creating awareness and brining change in attitude like other formats of communication. It can be really helpful in promoting healthy behavior among women and ultimately a healthy nation. Health is a worldwide issue and in a country like Pakistan i.e. underdeveloped, it is a huge problem. Women need to get awareness regarding certain health issues. It is important to know if women are really getting awareness or not through Public Service Awareness Messages about breast cancer, are the Public Service Awareness Messages changing the attitude of women towards their health for the preventive measures of breast cancer? Positive and continuous public service message strategies can bring favorable results in creating awareness among Pakistani women (Iftikhar, Aziz \& Yousaf, 2019). Furthermore it is required to know the need of improvement in the health related advertisements, especially focuses on the major disease that is breast cancer because it became very common in society.

\section{Significance of the Study}

Health has been an issue in Pakistan. This issue needs special attention. To tackle it carefully, Public Service Awareness Messages have proved to be very helpful. With the 
emergence of problems throughout the world, Public Service Awareness Messages have become a great importance in any society for addressing the social issues and creating awareness. No one can deny the importance of health for development of a nation. Pakistan is a country where so many health issues exist which require media attention. Public Service Awareness Messages are most effective tool of media advertising to aware the women about their health. As if women are healthy of any nation in turn it will make nation healthy and set it to the path of development (Gorman, Clapp, Calac, Kolander, Nyquist \& Chambers,2013).

\section{Hypotheses}

H1: Public Service Awareness Messages are motivating women to adopt precautionary measures against worst stage of cancer.

H2: Public Service Awareness Messages are changing the attitude and behavior of women to monitor themselves regularly.

H3: Women after getting Public Service Awareness Messages believe that precautionary measures will save them from worst stage of cancer.

\section{Review of Literature}

Public service advertising and messages are effective tool to educate people and motivate them to care about themselves. But this can be done only by the mutual collaboration of government, NGO's and public cooperation in the country like Pakistan where pubic behaviour towards health is not promising (Iftikhar \& Mughal, 2017). Advertising is indeed a tool not for commercial purpose rather to change the behaviour of the public by educating them (Zia \& Iftikhar, 2018). A substantial association exists between gender stereotype messages and media trustworthiness. The results evidently verified that gender stereotype messages are a considerable prognosticator to know about the change in behaviour of Pakistani public (Raza, Zaheer \& Iftikhar, 2019). Public service messages should be disseminated according to the cultural background of the women for desired results. In case of Pakistan if there is a congruence between public service awareness messages, social set setup, values, norms ethos and pathos of target audience can significantly change precautionary behavior of women with reference to Pakistan (Raza, Awan \& Iftikhar, 2018). In Pakistan corporate sector and advertisers are also working with breast cancer organizations to motivate women to care about themselves. This led them to encourage corporate social responsibility based advertising which always leave long lasting marks on the minds of Pakistani people (Iftikhar, Awam \& Hamid, 2019).

There is a serious requirement for a well sustained campaign to make masses aware about Breast Cancer. (Omotara, Yahya, Amodu \& Bimba, 2012) Women's knowledge and practice of self-examination to detect breast cancer is insufficient. Direct edification 
actions are to be executed to increase early detection of breast cancer (Parsa \& Kandiah, 2005). Numerous obstacles are in the way that hinders the behavioral changes in term of taking precautions. They may lead to impediments to acquire knowledge. Health workers and planner need to encourage women to change their screening behavior (Amin, Al Mulhim \& Al Meqihwi, 2009). Breast Cancer is greatest common cancer causing deaths and indisposition in women. (Doumit, Fares \& Arevian, 2017) (Amin, Al Mulhim, \& Al Meqihwi, 2009). Breast cancer knowledge, risk factors and screening among adult Saudi women in a primary health care setting.

The first and foremost need of time is to increase health services for cancer control in developing countries. (Hanna \& Kangolle, 2010). Health organizations should design some strategies to communicate with females and to convince them for screening and to educate them concerning the significance of screening. (Othman, Ahram, Al-Tarawneh \& Shahrouri, 2015) Health education movements are authoritative to explicate the public on the causes, risk issues and deterrence of breast cancer (Suh, Atashili, Fuh \& Eta, 2012).

Educational programs are urgently required to raise women's devotion to breast cancer screening programs (El Mhamdi, Bouanene, Mhirsi, Sriha, Salem \& Soltani, 2013). Breast cancer detection awareness campaigns are supposed to be amended and focused towards more well-organized and embattled exploitation of resources. Healthcare professionals are important part of all this movement (Elobaid, Aw, Grivna \& Nagelkerke, 2014).

The prevalence of breast cancer, its configuration and survival rate is different in different countries. In Pakistan, it is very alarming that prevalence, termination stage and least survival rates are commonly observed and main reasons are lack of resources and unawareness. If a proper plan is designed in form of effective awareness campaign on media and institutions then favorable results can be achieved at long term bases (Khokher, Qureshi, Mahmood, Saleem \& Mahmud, 2011).

Another dilemma in reporting this disease are numerous social behaviour in terms of shyness, hesitation and stereotyped obscurantism in society (Naqvi, Zehra, Ahmad \& Ahmad, 2016). Urban women validates more positive approach in precautionary attitude towards breast cancer than rural Pakistani women (Gangane, Ng. \& Sebastian, 2015). Breast Cancer awareness among females in India was suboptimal and was related with the education. Awareness must be radically amplified via municipal outreach at initial stages and media should be used first to fight this killing diseases (Dey, Mishra, Govil \& Dhillon, 2015).

A study conducted in Karachi on female medical workers show outrageous results that medical worker women in public sector have got only $35 \%$ of proper awareness to care 
the breast cancer patient. This recommends that medical curriculum should be revised so that appropriate awareness shall be provided. It will help to spread awareness to general public with oral communication (Ahmed, Mahmud, Hatcher \& Khan, 2006). (Kakarala, Rozek, Cote, Liyanage \& Brenner, 2010) conducted a study on South Asian diaspora including Indian and Pakistani women divulges that breast cancer is detected more in Indian and Pakistani as compared to Caucasians. This predicts that south Asian women are not conscious to examine themselves having been aware about this devastating diseases, shows their lack of precautionary behavior. Proper communication strategies may affect the preventive behavior if they are disseminated properly. Pakistani women between aged 20-40 years showed a significant relationship between detection of breast cancer. Advertising educational message that are being broadcasted by television during a specific period of time (Iftikhar, Aziz \& Yousaf, 2019).

The ratio of women who are conscious in regular breast Self-Examination is low in developing countries as compared to developed nations. Therefore more efforts should be done to increase the contribution of health workforce in public on ground level (Poniedziałek et. al., 2014). Consistent apprise courses for health workers and media communication strategies are premeditated for the information provision regarding breast cancer. Health worker can be able to disseminate information to the people with the collaboration of media as well (Akhigbe \& Omuemu, 2009).Considerable number of women population still remains unaware of breast cancer problems, a good number of those who have knowledge were yet to translate knowledge and attitudes into practice (Azubuike \& Okwuokei, 2013).

Women education about the danger of breast cancer and importance of screening should be developed for the early detection of breast cancer (Tariq, Khubaib, Imran \& Ibrahim, 2011).Attentive actions are operative to increase the information of women and well influence is allied with higher education and youthfulness of women (Khokher et. al., 2015).

Pakistani society possesses Islamic culture and talking about breasts amenably is considered repugnant among females and rest of the society in general. This social and cultural behavior prevents them to think about taking care of this organ or to tell if any problem is suspected. Another factor is lack of proper technical knowledge as inquisition to know about breast health or cancer appears to be disconcerting (Banning \& Hafeez, 2009). Psychological problem can be a problem in creating a precautionary behavior among women by giving them spiritual education and counselling to the families of victims (Banning \& Tanzeen, 2019). A very recent and important study conducted by (Khan, Siddique, Shahid, Khokher \& Fatima, 2018), figured out another fact about the economic position of the people is a variable to motivate masses to care about themselves and due to increase in cost of medical care women of middle and lower income class who intentionally ignore self-care and self-examination to avoid the diagnosis of the diseases. 
South Asian particularly Indian urban women who are considered more known and educated too, had a low knowledge scrutinized by (Somdatta \& Baridalyne, 2008). Their education should be increased to develop precautionary behavior for the early detection of this outrageous disease. A comparison has been dissected and data was collected from different countries, where a clear difference among various countries have been seen. According to statistical data, the graph of breast cancer self-examination is more in west where US was at the top up to $75 \%$, around $35 \%$ in Middle East but unfortunately only $14 \%$ in Pakistan. One of the lower ones in the world (Rizwan \& Saadullah, 2009).

Theory of Planned Behavior (TPB)is the extension of the theory of reasoned action (TRA) (Fishbein, Jaccard, Davidson, Ajzen \& Loken 1980), elaborates that any interference endeavoring to change behavior is related with the emphasis on beliefs, as these stimulate attitudes and opportunities and in turn intentions and behaviors. Later, it was projected that behaviors are not under 'volitional control' and the model was revisited and extended to contain 'perceived behaviour control' (Open University Press, Buckingham, 2002). The modification of reasoned action theory was the sordid of the development of the planned behavior theory. TPB states that "the closest determinant of behavior is the intention to perform (or not perform) that behavior" (Lavin \& Groarke, 2005). The primary constituent to this model is behavioral intent. TPB has been recycled effectively to predict and elucidate an extensive assortment of health related behaviors and intentions including drug addiction, alcoholic addiction, smoking, breastfeeding etc. The TPB is comprised of six constructs that together signify a person's actual control over the behavior including attitudes, behavioral intention, subjective norms, social norms, perceived power and perceived behavioral control.

The TPB has been used in many studies to find out behavior like walking among sedentary adults, stop smoking, "a predictor of exercise take-up" (Kelley, \& Abraham, 2004) inspiration for physical activity, "dental floss behavior" (Lavin \& Groarke, 2005) and others. In 1974, Becker established the health belief model (HBM) from the work of Rosenstock (1966). The Health Belief Model (HBM) is one of the extensively applied theoretical frameworks in studying health behavior. (Strecher \& Rosenstock, 1997) It has been applied successfully with great accomplishment for many decades to promote health related behaviors.

It is a framework for inspiring females to take optimistic health initiatives in order to avoid a negative health position as major objective of their lives in form of health related education. Numerous studies have been carried based on HBM-as prevention programs published between 1974 and 1984, that targeted different varieties of health programs (Becker, 1974). 


\section{Research Methodology}

Quantitative research method is used for the study of "Role of Public Service Messages Developing the Precautionary measures of Women of Lahore towards Breast Cancer". Primary data has been collected through survey. Questionnaire was the tool of the survey with close ended questions to reach the opinions of target audience. The population of the study was healthy female residents of Lahore and a sample of 300 women have been drawn randomly for the study. The unit of analysis in this study is Public Service Awareness Messages of breast cancer. The impact of the independent variable Public Service Awareness Messages is studied on Attitude and Behavior. Statistical test Pearson correlations have been used to find the correlation between the variables.

\section{Finding and Results}

This study measured the Pakistani women's knowledge about breast cancer and precautionary measures of breast cancer in them. It also measured the behavioral intention of women about watching the public service awareness messages related to breast cancer.

\section{Hypotheses Testing}

$\mathrm{H}_{1}$ : Public Service Awareness Messages (PSAMs) are motivating (M) women to adopt precautionary measures against worst stage of cancer.

\section{Table:1}

\begin{tabular}{|c|c|c|c|c|}
\hline & & $\begin{array}{l}\text { Dependent } \\
\text { (M) }\end{array}$ & $\ldots$ & $\begin{array}{l}\text { Independent } \\
\text { (PSAMs) }\end{array}$ \\
\hline Dependent (M) & $\begin{array}{l}\text { Pearson } \\
\text { Correlation } \\
\text { Sig. } \\
\text { tailed }) \\
\mathrm{N}\end{array}$ & $\begin{array}{c}1 \\
300\end{array}$ & $\ldots$ & $\begin{array}{l}.446^{* *} \\
.000 \\
300\end{array}$ \\
\hline $\begin{array}{l}\text { Independent } \\
\text { (PSAMs) }\end{array}$ & $\begin{array}{l}\text { Pearson } \\
\text { Correlation } \\
\text { Sig. } \\
\text { tailed }) \\
\mathrm{N}\end{array}$ & $\begin{array}{l}.446^{* *} \\
.000 \\
300\end{array}$ & $\ldots$ & $\begin{array}{l}1 \\
300\end{array}$ \\
\hline
\end{tabular}

**. Correlation is significant at the 0.01 level (2-tailed).

This table shows a significant relationship between dependent variable (M) and independent variable (PSAMs). The value of Pearson correlation as 0.446 with the $p$ value 0.01, shows that Public Service Awareness Messages motivate women to adopt the precautionary measures which means the Hypothesis 1 is correct. 
$\mathbf{H}_{2}$ : Public Service Awareness Messages (PSAMs) are changing the attitude and behavior $(\mathrm{AB})$ of women to monitor themselves regularly.

Table: 2

\begin{tabular}{|c|c|c|c|c|}
\hline & & $\begin{array}{l}\text { Dependent } \\
\text { (AB) }\end{array}$ & $\ldots$ & $\begin{array}{l}\text { Independent } \\
\text { (PSAMs) }\end{array}$ \\
\hline $\begin{array}{l}\text { Dependent } \\
\text { (AB) }\end{array}$ & $\begin{array}{l}\text { Pearson } \\
\text { Correlation } \\
\text { Sig. } \\
\text { tailed) } \\
\mathrm{N}\end{array}$ & $\begin{array}{l}1 \\
300\end{array}$ & $\ldots$ & $\begin{array}{l}.435^{* *} \\
.000 \\
300\end{array}$ \\
\hline $\begin{array}{l}\text { Independent } \\
\text { (PSAMs) }\end{array}$ & $\begin{array}{l}\text { Pearson } \\
\text { Correlation } \\
\text { Sig. } \\
\text { tailed) } \\
\mathrm{N}\end{array}$ & $\begin{array}{l}.435^{* *} \\
.000 \\
300\end{array}$ & $\ldots$ & $\begin{array}{l}1 \\
300\end{array}$ \\
\hline
\end{tabular}

**. Correlation is significant at the 0.01 level (2-tailed).

In Table-II, a considerable relationship is demonstrated between dependent variable (AB) and independent variable (PSAMs). The value of Pearson correlation is 0.435 at 0.01 , shows positive correlation that is in favor of alternative hypothesis. Hence, Hypothesis 2 is accepted.

$\mathbf{H}_{3}$ : Women after getting Public Service Awareness Messages (PSAMs)believe (BV) that precautionary measure will save them from worst stage of cancer.

Table: 3

\begin{tabular}{|c|c|c|c|c|}
\hline & & $\begin{array}{l}\text { Dependent } \\
\text { (BV) }\end{array}$ & $\ldots$ & $\begin{array}{l}\text { Independent } \\
\text { (PSAMs) }\end{array}$ \\
\hline Dependent (BV) & $\begin{array}{l}\text { Pearson } \\
\text { Correlation } \\
\text { Sig. } \\
\text { tailed) } \\
\mathrm{N}\end{array}$ & $\begin{array}{l}1 \\
300\end{array}$ & $\ldots$ & $\begin{array}{l}.335 * * \\
.000 \\
300\end{array}$ \\
\hline $\begin{array}{l}\text { Independent } \\
\text { (PSAMs) }\end{array}$ & $\begin{array}{l}\text { Pearson } \\
\text { Correlation } \\
\text { Sig. } \\
\text { tailed) } \\
\text { N }\end{array}$ & $\begin{array}{l}.335 * * \\
.000 \\
300\end{array}$ & $\ldots$ & $\begin{array}{l}1 \\
300\end{array}$ \\
\hline
\end{tabular}

**. Correlation is significant at the 0.01 level (2-tailed). 
The above mentioned table shows a significant relationship between dependent variable (BV) and independent variable (PSAMs). The value of Pearson correlation 0.335 at 0.01 that results in favor of our research hypothesis. Hence Hypothesis 3 is accepted.

\section{Discussion and Analysis}

The analysis of the data collected through survey has been recorded. The study comprised on 54\% married respondents and 45.33\% unmarried and 99\% are Muslims and only 1\% Non-Muslims. Majority of respondents are from Middle Class i.e. 80\%, 14.67\% respondents are from high class and 5.33\% respondents are from lower class. Most of the women, $71.33 \%$ are much conscious about their health, $1 \%$ respondents are not conscious and $27 \%$ respondents are sometimes conscious. Results show that $49.67 \%$ respondents are familiar with health related ads or messages, $31.67 \%$ respondents have watched public service awareness messages about breast cancer, $5.67 \%$ respondents have watched ad or public service awareness message about TB, 9.33\% respondents have watched public service awareness message about hepatitis and $3.67 \%$ respondents have not come across any message about breast cancer in any foam. The data highlighted that large number of respondents have watched health ads or PSAMs on all these diseases.

Majority of the respondents $42.33 \%$ have watched PSAM on breast cancer on television, $13.00 \%$ respondents have watched pamphlet, $18.00 \%$ respondents have watched brochure, and $13.33 \%$ respondents have watched poster foam and $13.33 \%$ respondents have watched banner of breast cancer precautions. Among the respondents, 38.00\% have agreed that while watching the health ads, they should pay attention to the instructions which are given in Public Service Awareness Messages, 31\% have strongly agreed with this statement, $21.67 \%$ respondents are neutral, $2.67 \%$ respondents disagreed with this statement and $6.67 \%$ respondents strongly disagreed with this statement. The data highlighted that large number of respondents think they should pay attention to those instructions which are given in Public Service Awareness Messages while watching the health ads.

The analysis shows that 38\% respondents agreed that information in PSAMs on Breast cancer create fear among women and make them conscious about their health, $8.33 \%$ respondents strongly agreed, 35\% respondents were neutral, $15.67 \%$ disagreed and 3\% strongly disagreed. PSAMs about breast cancer are useful tool to educate women was strongly agreed by $28 \%$ respondents, agreed by $50 \%$ respondents, disagreed by $11.67 \%$ and strongly disagreed by $1 \%$ and other $9.33 \%$ were neutral. A large segment of respondents i.e. $26.33 \%$ respondents agreed that PSAMs are significantly educating women and providing awareness about breast cancer, $26.33 \%$ strongly agreed, $14.67 \%$ were neutral, $5 \%$ disagreed and $4.33 \%$ strongly disagreed. The results further show that $45.33 \%$ respondents agreed that health related ads influence women to follow the instructions given in them, $19.67 \%$ strongly agreed, $25 \%$ were neutral, $8.67 \%$ disagreed and $1.33 \%$ strongly disagreed. 
Majority of the respondents got much knowledge about precautionary measures about breast cancer as $24.33 \%$ agreed on it, 5\% strongly agreed, $37 \%$ were neutral, while other $31.33 \%$ disagreed and $2.33 \%$ strongly disagreed. Among them 13\% respondents agree that there is no need of preventive measures about breast cancer, 3.33\% respondents strongly agree, $10.33 \%$ respondents showed their neutral behavior, $32.67 \%$ respondents disagree and $40.33 \%$ respondents strongly disagree. Among the respondents $21.67 \%$ agreed that they feel that they will develop breast cancer; after watching PSAMs, $6.33 \%$ strongly agreed, $30.33 \%$ were neutral, $29.33 \%$ disagreed and $12.33 \%$ strongly disagreed.

The analysis and findings revealed that 52\% respondents agreed that health related ads about breast cancer change their attitude towards their selves after getting knowledge from them, $17.67 \%$ strongly agreed, $21 \%$ were neural, $8.33 \%$ disagreed and $1 \%$ strongly disagreed. The figures show that $45 \%$ respondents agreed that they become conscious after watching PSAMs, 21.67\% strongly agreed, 21.67\% were neutral, $8.67 \%$ disagreed and 3\% strongly disagreed. Majority of them become afraid after watching PSAMs as $33.33 \%$ agreed, $18.33 \%$ strongly agreed, $26.33 \%$ were neutral, $19.67 \%$ disagreed and $2.33 \%$ strongly disagreed. Among the respondents $44.67 \%$ agreed that they ever make intention to monitor their body on monthly basis, $10.33 \%$ strongly agreed, $23.67 \%$ were neutral, $20.67 \%$ disagreed and $0.67 \%$ strongly disagree that means they actually become conscious and take precautionary measure.

Majority of the respondents found precautionary measures in PSAMs useful for breast cancer as $50.67 \%$ agreed, $19.67 \%$ strongly agreed, $18.67 \%$ were neutral, $9.33 \%$ disagreed and $1.67 \%$ strongly disagreed. Also, majority of them think that they can get caught by worst stage of breast cancer by not paying attention to these precautionary messages as $40.33 \%$ respondents agreed, $8.67 \%$ strongly agreed, $22.33 \%$ were neutral, $22.00 \%$ disagreed and $6.67 \%$ respondents strongly disagreed. The survey results found that most of the people think that if they take precautionary measures, they can prevent it while having family history of breast cancer; $32 \%$ respondents agreed to this, $25.67 \%$ strongly agreed, 20\% were neutral, $20.67 \%$ disagreed and $1.67 \%$ strongly disagreed.

Further results found that 35\% respondents agreed that if they are not health conscious then they will be ignorant to become breast cancer patient, $10 \%$ strongly agreed, $24 \%$ were neutral, $26.67 \%$ disagreed and $4.33 \%$ strongly disagreed. They also believe that preventive measures can improve health as $51.67 \%$ respondents agreed, $23 \%$ strongly agreed, $18 \%$ were neutral, $6 \%$ disagreed and $1.33 \%$ strongly disagreed. Most of them agreed that health related messages are changing the attitude and behavior of women regarding their health, as $15 \%$ agreed, $23 \%$ strongly agreed, $17.33 \%$ were neutral, $8 \%$ disagreed and $0.67 \%$ strongly disagreed. Finally, the results found that $44.33 \%$ respondents agreed that they should follow the instructions which are given in PSAMs to stay safe, $20.33 \%$ strongly agreed, 19\% were neutral, $14.33 \%$ disagreed and $2 \%$ strongly disagreed. 
It was revealed that health related ads or awareness messages change attitude and behavior of women towards their health. PSAMs are creating awareness about health issues among women. They perceive the information given in PSAMs and they adopt and then implement that information. Public Service Awareness Messages role for creating awareness among society is admirable especially health awareness as they are giving awareness and improving the community health. It is explored that most women think, they should follow the instructions given in those PSAMs to prevent risks and worst conditions.

It is concluded that PSAMs are creating awareness regarding breast cancer among women and precautionary measures of breast cancer is increased after watching them. Health of the women improved by PSAMs and most of women adopted the instructions provided in PSAMs of breast cancer. Majority of the respondents take care of their health and large number of women are becoming more conscious about their health after watching PSAMs regarding breast cancer. The hypotheses of the study have been supported by the findings and it is found that public service awareness messages are creating awareness of precautionary measures among women regarding breast cancer, change in behavior and attitude of women regarding breast cancer preventive measures.

\section{Conclusions}

The basic target of this study was to define the level of awareness of breast cancer among women and precautionary measures of breast cancer in women and also to measure the behavioral intention of women after watching Public Service Awareness Messages related to breast cancer. After watching advertising on breast cancer, women have knowledge how they can adopt precautionary measures in detection of breast cancer, and find out the change in the behavior of women towards their health issues through these messages. It is established that health related public service awareness messages about breast cancer are co-related in developing health awareness among women, majority of respondents watch PSAM related to breast cancer.

The findings and analysis of the data collected through survey of 300 women of Lahore have supported all the hypotheses of the research and answered all the research questions. Public Service Awareness Messages on breast cancer have given a lot of information and precautionary measures about breast cancer to women. Public Service Awareness Messages are changing the attitude and behavior of women for self-care. Information in awareness messages about breast cancer creates fear among women to make them conscious about their health. Majority of women pay attention to the messages and follow the instructions which are given to them. Women after getting Public Service Awareness Messages believe that precautionary measures can save them from worst stage of cancer and this makes them quite conscious about themselves. 
Moreover, respondents considered health related awareness messages given by Ministry of Health are reliable. However, some respondents either could not apply timely instructions or could not adopt it due to some financial constraint, sociological reasons and carelessness. PSAMs are the important tool for Government and NGO's for creating awareness about health issues among women. In the light of all findings and results it is observed that Government and NGO's are successfully educating the women and creating awareness among them about breast cancer. Precautionary measures of breast cancer are increased after watching PSAMs, women have changes their behavior and they became more conscious about their health after health-related ads or messages.

\section{Limitations}

The study was majorly based on the population of city of Lahore, which is one of the most developed cities of Pakistan. It should also be conducted in small cities and rural areas.

\section{Recommendations}

To gather more appropriate results on this research, it is necessary to conduct such studies in different regions and provinces to Pakistan to know about people's perception about PSAMs on breast cancer so that attitude of different people of Pakistan can be analyzed as a whole.

\section{References}

Ahmed, F., Mahmud, S., Hatcher, J. \& Khan, S. M. (2006). Breast Cancer Risk Factor Knowledge among Nurses in Teaching Hospitals of Karachi, Pakistan: A CrossSectional Study. BMC Nursing, vol.5:1, p.6.

Akhigbe, A. O. \& Omuemu, V. O. (2009). Knowledge, Attitudes and Practice of Breast Cancer Screening among Female Health Workers in aNigerian Urban City. BMC Cancer, vol.9:1, p.203.

American Cancer Society, Inc. What are the Risk Factors for Breast Cancer? (2006). Retrieved June 21, 2007 from http://www.cancer.org/docroot/CRI/content/CRI_2 _4_2X_What_are_the_risk_factors_for_breast_cancer_5.asp?sitearea $1 / 4$

Amin, T. T., Al Mulhim, A. R. \& Al Meqihwi, A. (2009). Breast Cancer Knowledge, Risk Factors and Screening among Adult Saudi Women in a Primary Health Care Setting. Asian Pac J Cancer Prev, vol.10:1, pp.133-8. 
Azubuike, S. O. \& Okwuokei, S. O. (2013). Knowledge, Attitude and Practices of Women Towards Breast Cancer in Benin City, Nigeria. Annals of Medical And Health Sciences Research, vol.3:2, pp.155-160.

Banning, M. \&Hafeez, H. (2009). Perceptions of Breast Health Practices in Pakistani Muslim Women. Asian Pac J Cancer Prev, vol.10:5, pp.841-7.

Banning, M. \& Tanzeem, T. (2013). Managing the Illness Experience of Women with Advanced Breast Cancer: Hopes and Fears of Cancer $\square$ Related Insecurity. European Journal of Cancer Care, vol.22:2, pp.253-260.

Banning, M. \& Tanzeen, T. (2019). Living with Advanced Breast Cancer: Perceptions of Pakistani Women on Life Expectations and Fears. Cancer Nursing, vol.37:1, pp.E12-E18.

Becker, G. S. (1974). A Theory of Social Interactions. Journal of Political Economy, vol.82:6, pp.1063-1093.

Chaffee, S. H. (1982). Mass Media and Interpersonal Channels: Competitive, Convergent, or Complementary. Inter/Media: Interpersonal Communication in a Media World, pp.57-77.

Coughlin, S. S. \& Ekwueme, D. U. (2009). Breast Cancer as a Global Health Concern. Cancer Epidemiology, vol.33:5, pp.315-318.

Da Costa Vieira, R. A., Biller, G., Uemura, G., Ruiz, C. A. \& Curado, M.P. (2017). Breast Cancer Screening in Developing Countries. Clinics,vol.72:4, pp.244-253.

Dey, S., Mishra, A., Govil, J. \& Dhillon, P. K. (2015). Breast Cancer Awareness at the Community Level among Women in Delhi, India. Asian Pac J Cancer Prev, vol.16:13, pp.5243-51.

Dornbusch, D. (1998). An Analysis of Media Coverage of the BSE Crisis. The Mad Cow Crisis: Health and the Public Good,pp.138-152.

Doumit, M. A., Fares, S. \& Arevian, M. (2017). Knowledge, Practices and Attitudes of Women toward Breast Cancer in Lebanon. American Journal of Hematology/Oncology, vol.13:7. 
Dutta-Bergman, M. J. (2004). Primary Sources of Health Information: Comparisons in the Domain of Health Attitudes, Health Cognitions and Health Behaviors. Health Communication, vol.16:3, pp.273-288.

El Mhamdi, S., Bouanene, I., Mhirsi, A., Sriha, A., Salem, K. B. \& Soltani, M. S. (2013). Women's Knowledge, Attitudes and Practice about Breast Cancer Screening in the Region of Monastir (Tunisia). Australian Journal of Primary Health, vol.19:1, pp.68-73.

Elobaid, Y. E., Aw, T. C., Grivna, M. \& Nagelkerke, N. (2014). Breast Cancer Screening Awareness, Knowledge and Practice among Arab Women in the United Arab Emirates: ACross-Sectional Survey. PloS One, vol.9:9.

Ferlay, J., Soerjomataram, I., Dikshit, R., Eser, S., Mathers, C., Rebelo, M. \& Bray, F. (2015). Cancer Incidence and Mortality Worldwide: Sources, Methods and Major Patterns in GLOBOCAN 2012. International Journal of Cancer, vol.136:5, pp.E359-E386.

Fishbein, M., Jaccard, J., Davidson, A. R., Ajzen, I. \& Loken, B. (1980). Predicting and Understanding Family Planning Behaviors. In Understanding Attitudes and Predicting Social Behavior. Prentice Hall.

Gangane, N., Ng, N. \& Sebastian, M. S. (2015). Women's Knowledge, Attitudes and Practices about Breast Cancer in a Rural District of Central India. Asian Pacific Journal of Cancer Prevention, vol.16:16, pp.6863-6870.

Global Burden of Disease Cancer Collaboration. (2015). The Global Burden of Cancer 2013. JAMA Oncology, vol.1:4, p.505.

Gorman, J. R., Clapp, J. D., Calac, D., Kolander, C., Nyquist, C. \& Chambers, C. D. (2013). Creating a Culturally Appropriate Web-Based Behavioral Intervention for American Indian/Alaska Native Women in Southern California: The Healthy Women Healthy Native Nation Study. American Indian and Alaska Native Mental Health Research: The Journal of the National Center, vol.20:1, pp.1-15.

Hanna, T. P. \& Kangolle, A. C. (2010). Cancer Control in Developing Countries: Using Health Data and Health Services Research to Measure and Improve Access, Quality and Efficiency. BMC International Health and Human Rights, vol.10:1, p.24. 
Henderson, L. \& Kitzinger, J. (1999). The Human Drama of Genetics: 'Hard' and 'Soft' Media Representations of Inherited Breast Cancer. Sociology of Health \& Illness, vol.21:5, pp.560-578.

International Agency for Research on Cancer. (2008). GLOBOCAN 2008: cancer incidence and mortality worldwide in 2008. http://globocan. iarc. fr/.

Iftikhar, M., Awam, U. \& Hamid, S. (2019). A Wave of Change: Socially Responsible Advertising Influence on the Buying Behavior and Social Development in Pakistan. Journal of Arts and Social Sciences, vol.VI:1, pp.95-111.

Iftikhar, M., Aziz, F. \& Yousaf, Z. (2019). Role of Breast Cancer Awareness Advertising Educational Messages in Educating Women to Develop a Precautionary Behavior. Sjesr, vol.2:2, pp.66-80.

Iftikhar, M. \& Mughal, M. K. (2017). Role of Public Service Educational Messages in Educating People about the Perceived Risk of Hepatitis. Journal of Mass Communication Department,Dept of Mass Communication, University of Karachi, vol. 16, pp. 25-45.

Kakarala, M., Rozek, L., Cote, M., Liyanage, S. \& Brenner, D. E. (2010). Breast Cancer Histology and Receptor Status Characterization in Asian Indian and Pakistani Women in the US-a SEER Analysis. BMC Cancer, vol.10:1, p.191.

Katkuri, S. \& Gorantla, M. (2018). Awareness about Breast Cancer among Women Aged 15 Years and Above in Urban Slums: A Cross Sectional Study. International Journal of Community Medicine and Public Health, vol.5:3, pp.929-932.

Kaushal, N., Langlois, F., Desjardins-Crépeau, L., Hagger, M. S. \& Bherer, L. (2019). Investigating Dose-Response Effects of Multimodal Exercise Programs on Health-Related Quality of Life in Older Adults. Clinical Interventions in Aging, vol.14, p.209.

Kelley, K. \& Abraham, C. (2004). RCT of a Theory-Based Intervention Promoting Healthy Eating and Physical Activity Amongst Out-Patients Older Than 65 Years. Social Science \& Medicine, vol.59:4, pp.787-797.

Khan, R. T., Siddique, A., Shahid, N., Khokher, S. \& Fatima, W. (2018). Breast Cancer Risk Associated with Genes Encoding DNA Repair MRN Complex: AStudy from Punjab, Pakistan. Breast Cancer, vol.25:3, pp.350-355. 
Khokher, S., Qureshi, M. U., Fatima, W., Mahmood, S. \& Saleem, A. (2015). Impact of a Breast Health Awareness Activity on the Knowledge Level of the Participants and its Association with Socio-Demographic Features. Asian Pacific Journal of Cancer Prevention, vol.16:14, pp.5817-5822.

Khokher, S., Qureshi, W., Mahmood, S., Saleem, A. \& Mahmud, S. (2011). Knowledge, Attitude and Preventive Practices of Women for Breast Cancer in the Educational Institutions of Lahore, Pakistan. Asian Pac J Cancer Prev, vol.12:9, pp.2419-24.

Klimes-Dougan, B., \& Lee, C. Y. S. (2010). Suicide prevention public service announcements: Perceptions of young adults. Crisis: The Journal of Crisis Intervention and Suicide Prevention, vol.31:5, pp. 247.

Lavin, D. \& Groarke, A. (2005). Dental Floss Behaviour: A Test of the Predictive Utility of the Theory of Planned Behaviour and the Effects of Making Implementation Intentions. Psychology, Health \& Medicine, vol.10:3, pp.243-252.

Linsell, L., Burgess, C. C. \& Ramirez, A. J. (2008). Breast Cancer Awareness among Older Women. British Journal of Cancer, vol.99:8, pp.1221-1225.

MacKenzie, R., Chapman, S., Barratt, A. \& Holding, S. (2007). The News is [not] all Good: Misrepresentations and Inaccuracies in Australian News Media Reports on Prostate Cancer Screening. Medical Journal of Australia, vol.187:9, pp.507-510.

Moynihan, R., Bero, L., Ross-Degnan, D., Henry, D., Lee, K., Watkins, J. \& Soumerai, S. B. (2000). Coverage by the News Media of the Benefits and Risks of Medications. New England Journal of Medicine, vol.342:22, pp.1645-1650.

Nakahara, S., Ichikawa, M. \& Wakai, S. (2007). Magazine Information on Safety Belt Use for Pregnant Qomen and Young Children. Accident Analysis \& Prevention, vol.39:2, pp.356-363.

Naqvi, A. A., Zehra, F., Ahmad, R. \& Ahmad, N. (2016). Developing a Research Instrument to Document Awareness, Knowledge and Attitudes Regarding Breast Cancer and Early Detection Techniques for Pakistani Women: The Breast Cancer Inventory (BCI). Diseases, vol.4:4, p.37.

Ogata Jones, K., Denham, B. E. \& Springston, J. K. (2006). Effects of Mass and Interpersonal Communication on Breast Cancer Screening: Advancing AgendaSetting Theory in Health Contexts. Journal of Applied Communication Research, vol.34:1, pp.94-113. 
Omotara, B., Yahya, S., Amodu, M. \& Bimba, J. (2012). Awareness, Attitude and Practice of Rural Women Regarding Breast Cancer in Northeast Nigeria. $J$ Community Med Health Educ, vol.2:5, pp.1-4.

Othman, A., Ahram, M., Al-Tarawneh, M. R. \& Shahrouri, M. (2015). Knowledge, Attitudes and Practices of Breast Cancer Screening among Women in Jordan. Health Care for Women International, vol.36:5, pp.578-592.

Parsa, P. \& Kandiah, M. (2005). Breast Cancer Knowledge, Perception and Breast SelfExamination Practices among Iranian Women. Int Med J, vol.4:2, pp.17-24.

Poniedziałek, B., Rebelka, M., Makowska, K., Piotrowska, J., Karczewski, J. \& Rzymski, P. (2014). Do We Need to Improve Breast Cancer Education? Attitude towards Breast Self-examination and Screening Programmes among Polish Women. Journal of Medical Science, vol.83:4, pp.313-317.

Pruitt, S. L. \& Mullen, P. D. (2005). Contraception or Abortion? Inaccurate Descriptions of Emergency Contraception in Newspaper Articles, 1992-2002. Contraception, vol.71:1, pp.14-21.

Raza, S. H., Awan, S. M. \& Iftikhar, M. (2018). Effect of the Cultural Gender Role Orientation on Advertising Intrusiveness and the Moderating effect of SelfReferencing: An Experimental Study. Journal of the Research Society of Pakistan, vol.55:1.

Raza, S. H., Zaheer, L. \& Iftikhar, M. (2019). Gender Stereotype News in Context of the Ethnicity: Scale Development and Validation. Pakistan Journal of Psychological Research, vol.34:1.

Rizwan, M. \& Saadullah, M. (2009). Lack of Awareness about Breast Cancer And its Screening in Developing Countries. Indian Journal of Cancer, vol.46:3, pp.252-252.

Sagi, M., Kaduri, L., Zlotogora, J. \& Peretz, T. (1998). The Effect of Genetic Counseling on Knowledge and Perceptions Regarding Risks for Breast Cancer. Journal of Genetic Counseling, vol.7:5, pp.417-434.

Siegel, R. L., Miller, K. D. \& Jemal, A. (2019). Cancer Statistics, 2019. CA: ACancer Journal for Clinicians, vol.69:1, pp.7-34.

Somdatta, P. \& Baridalyne, N. (2008). Awareness of Breast Cancer in Women of an Urban Resettlement Colony. Indian Journal of Cancer, vol.45:4, p.149. 
Stretcher, V. \& Rosenstock, I. M. (1997). The Health Belief Model. In K. Glanz, F. M. Lewis, \& B. K. Rimer (Eds.), Health behavior and health education: Theory, research and practicevol. 23:8, pp. 48-54. San Francisco, CA: Jossey-Bass.

Suh, M. A. B., Atashili, J., Fuh, E. A. \& Eta, V. A. (2012). Breast Self-Examination and Breast Cancer Awareness in Women in Developing Countries: ASurvey of Women in Buea, Cameroon. BMC research notes, vol.5:1, p.627.

Tariq, M. M., Khubaib, S., Imran, A. B. \& Ibrahim, M. (2011). Screening Mammography for Breast Cancer in Women Using Bi-RADS Scores.Iranian Journal of Cancer Prevention, vol. 4:1, pp. 20-25

Wallack, L. \& Dorfman, L. (1992). Health Messages on Television Commercials. American Journal of Health Promotion, vol.6:3, pp.190-196.

Zia, A. \& Iftikhar, M. (2018). Television Commercials as a Tool of Education: The Usage and Impact of Smartphones among Millennials. Journal of Research \& Reflections in Education (JRRE), vol.12:2.

Moneeba Iftikhar is Lecturer in the Department of Mass Communication, Lahore College for Women University, Lahore, Pakistan.

Dr. Zahid Yousaf is an Associate Professor and Chairperson in the Centre for Media and Communication Studies (CMCS), University of Gujrat, Gujrat, Pakistan. 